\title{
Delayed visual maturation
}

\author{
G F COLE, J HUNGERFORD, AND R B JONES
}

Children's Department, Moorfields Eye Hospital, London

SUMmARY Sixteen blind babies who were considered to be showing the characteristics of delayed visual maturation were studied prospectively. The diagnosis was made on clinical grounds, and the criteria for this are discussed. All of these infants developed visual responses between 4 and 6 months of age and had normal or near normal visual acuities by 1 year of age. Long term follow up, however, has shown neurological abnormalities in some of these children.

Delay in the development of normal visual responses has long been recognised in severely mentally retarded children ${ }^{1-4}$ and in those with visual agnosia. ${ }^{5}$ There are numerous anecdotal reports of delayed visual maturation occurring in apparently normal infants, ${ }^{16-8}$ although the condition has been well documented only by .Illingworth, ${ }^{9}$ Mellor and Fielder,$^{10}$ and, very recently, by Harel et al. ${ }^{11}$ and Hoyt et al. ${ }^{12}$ This study was undertaken to investigate the natural history of delayed visual maturation and define its diagnostic features, and to establish whether the affected children are in fact neurologically normal, as has been reported. ${ }^{81011}$

\section{Patients and methods}

The 16 infants in this study were referred between 1976 and 1982 to the Children's Department of Moorfields Eye Hospital by a general practitioner, paediatrician, or ophthalmologist because they were thought to be blind. At the first visit each infant was seen by an ophthalmologist and a developmental paediatrician. A careful history with particular reference to pregnancy, perinatal events, family history, and early developmental milestones was obtained. The ability to watch and follow a light or a large bright object was assessed, and an attempt was made to elicit optokinetic nystagmus with a striped drum. The reaction of the pupils to light was determined, and the presence or absence of abnormal eye movements was noted. The children were examined physically and a careful developmental assessment was also performed. The ocular fundi were assessed by binocular indirect ophthalmoscopy after instilling $1 \%$ cyclopentolate drops. Subsequently the infants were reviewed at monthly intervals until it was considered that they were showing appropriate visual responses and a quan- titative estimation of the visual acuity was made using the Catford drum. Early in the series, four of the babies were additionally subjected to examination of the eyes under anaesthesia partly so that electrodiagnostic tests could be performed. The electroretinogram was recorded in each of these children, and the cortical visually evoked response was also investigated. Follow up consisted of a comprehensive assessment of vision at approximately 1 year of age and developmental assessment by a paediatrician at 6 monthly or annual intervals. When it was considered necessary, the child was referred to a developmental assessment team at The Donald Winnicott Centre and seen by a psychologist, a speech therapist, a physiotherapist, an occupational therapist, and an audiologist.

\section{Results}

There were six girls and 10 boys and all were white. The parents of patient 3 were second cousins. All the babies presented as blind between 6 and 12 weeks of age, although most presented between 6 and 9 weeks. Three of the infants were preterm, and one of these had developed the idiopathic respiratory distress syndrome (patient 1). One mother took anticonvulsant drugs throughout the pregnancy (patient 15). There were no important common factors in the perinatal histories. Usually the parents were the first to notice the visual abnormality. They became concerned when their baby showed no response to visual stimuli, and several volunteered that the child responded by smiling to a voice but not to a face. Four babies' parents commented that the infant did not blink in response to flash photography.

At the first visit none of the infants fixed or followed a light or large bright object, and no 
108 Cole, Hungerford, and Jones

Table Clinical details of the patients

\begin{tabular}{|c|c|c|c|c|c|c|c|c|}
\hline Patient & Sex & $\begin{array}{l}\text { Gestational } \\
\text { age (weeks) }\end{array}$ & $\begin{array}{l}\text { Age at } \\
\text { presentation } \\
\text { (weeks) }\end{array}$ & $\begin{array}{l}\text { Age visual } \\
\text { responses } \\
\text { acquired } \\
\text { (weeks) }\end{array}$ & $\begin{array}{l}\text { Electrodiagnostic } \\
\text { tests }\end{array}$ & $\begin{array}{l}\text { Visual acuity } \\
\text { with both } \\
\text { eyes open }\end{array}$ & $\begin{array}{l}\text { Follow } \\
\text { up } \\
\text { (years) }\end{array}$ & Outcome \\
\hline 1 & $\mathbf{F}$ & 36 & 7 & 20 & $*$ & $6 / 9$ at 9 months & 5 & Normal development. Epilepsy \\
\hline 2 & $\mathbf{M}$ & Term & 10 & 20 & * & $6 / 6$ at 1 year & $51 / 2$ & $\begin{array}{l}\text { Normal development. Convergent squint } \\
\text { (no refractive error) }\end{array}$ \\
\hline 3 & $\mathbf{M}$ & Term & 11 & 16 & * & $6 / 12$ at 1 year & $41 / 2$ & Global retardation ESN (M) \\
\hline 4 & $\mathbf{F}$ & Term & 11 & 20 & * & $6 / 6$ at 1 year & 2 & $\begin{array}{l}\text { Normal development at } 2 \text { years. } \\
\text { Lost to follow up }\end{array}$ \\
\hline 5 & $\mathbf{F}$ & Term & 9 & 16 & & $6 / 6$ at 1 year & $21 / 2$ & $\begin{array}{l}\text { Normal development at } 21 / 2 \text { years. } \\
\text { Lost to follow up }\end{array}$ \\
\hline 6 & $\mathbf{M}$ & Term & 12 & 20 & & $6 / 6$ at 1 year & $21 / 2$ & $\begin{array}{l}\text { Normal Development. Convergent squint } \\
\text { (no refractive error) }\end{array}$ \\
\hline 7 & $\mathbf{M}$ & Term & 8 & 20 & & $6 / 6$ at 1 year & 6 & $\begin{array}{l}\text { Epilepsy. Horizontal + vertical } \\
\text { nystagmus. Squint }\end{array}$ \\
\hline 8 & $\mathbf{F}$ & 35 & 6 & 24 & & $6 / 6$ at 9 months & 3 & Normal development \\
\hline 9 & $\mathbf{M}$ & Term & 8 & 16 & & $6 / 6$ at 1 year & $31 / 2$ & Normal development. Speech delay \\
\hline 10 & $\mathbf{M}$ & Term & 9 & 16 & & $6 / 12$ at 9 months & $1 \frac{1}{2}$ & Normal development \\
\hline 11 & $\mathbf{F}$ & Term & 10 & 20 & & $6 / 9$ at 1 year & $31 / 2$ & Speech delay \\
\hline 12 & $\mathbf{M}$ & 36 & 12 & 18 & & $6 / 9$ at 9 months & 3 & $\begin{array}{l}\text { Normal development. } \\
\text { Psychogenic polydipsia }\end{array}$ \\
\hline 13 & $\mathbf{F}$ & Term & 7 & 16 & & $6 / 6$ at 1 year & $2^{1 / 2}$ & Normal development \\
\hline 14 & $\mathbf{M}$ & Term & 8 & 16 & & $6 / 6$ at 9 months & 1 & Normal development \\
\hline 15 & $\mathbf{M}$ & Term & 8 & 16 & & $6 / 6$ at 1 year & 2 & Normal development. Sleep disturbance \\
\hline 16 & $\mathbf{M}$ & Term & 12 & 24 & & $6 / 9$ at 9 months & 1 & Normal development \\
\hline
\end{tabular}

* Visually evoked response, electroretinogram.

optokinetic nystagmus could be found. All the babies had brisk pupillary responses to light. Three of the children had horizontal nystagmus (patients 2, 7 , and 8 ). On ophthalmoscopy every child had clear media and normal ocular fundi.

Electrodiagnostic tests were performed on four children (patients 1, 2, 3, and 4). Visual responses had developed in each of these patients in the time that elapsed between presentation and performance of these tests. Although the electroretinogram was normal in each instance the visually evoked response was not. This showed a normal latency but the configuration was abnormal. General anaesthesia provided the opportunity to examine in detail the ocular fundi of the four children, and the normal findings of the initial examination were confirmed.

Between the ages of 4 and 6 months all 16 babies became visually responsive, showing fixation and following ability, and optokinetic nystagmus could then be elicited. Between 9 and 12 months all the children were found to have normal or near normal visual acuities. In two of the three babies who had previously had nystagmus there were now no abnormal eye movements (patients 2 and 8 ). The third of these infants on longer follow up developed an additional vertical element to his nystagmus and a convergent squint with amblyopia (patient 7).

The children in this series have been followed for between one and six years. Two of the children (patients 4 and 5) were lost to follow up at ages 2 and $2^{1 / 2}$ years respectively, and at this time they were considered to be age appropriate in all developmental skills. One child was considered to be showing moderate general developmental delay at the age of 1 year. Psychometric testing at a later age established his full scale IQ to be within the ESN(M) range (patient 3). Of the remainder, all have age appropriate developmental skills or, where tested, a full scale IQ within the normal range. Several of these children have permanent neurological abnormalities. One boy has developed minor motor seizures (patient 1), and the child with nystagmus and squint also developed epilepsy at the age of 18 months (patient 7). In two other children (patients 2 and 6) convergent squints have also developed which are not due to refractive error. In addition to these frank neurodevelopmental problems, several children presented with behaviour problems, including one child with severe polydipsia. Two other children presented with delay in speech development.

\section{Discussion}

In a state of alert wakefulness the fixation reflex can be shown in a preterm infant at 32 weeks' gestation..$^{13} 14$ At this age, preferential looking behaviour is also present,$^{15}$ the infant preferring to look at a patterned or moving target rather than at an equally illuminated field. Horizontal tracking 
movements are present at birth, although vertical following does not develop until 4 to 6 weeks of age. Optokinetic nystagmus can be elicited at an even earlier age. ${ }^{16}$ It is a response to a target that excites visual interest by producing moving contours in the visual field, such as a rotating drum with alternate black and white stripes or a striped scarf. As the jerky nystagmus indicative of a positive response can be induced at a very early age, this is a valuable screening device. The presence of optokinetic nystagmus in an apparently normal infant indicates that the child is not blind, but its consistent absence provides evidence of a marked impairment of visual function.

Delay in the appearance of normal visual responses in the newborn should always be taken seriously. Approximately 40 new cases of blind or severely visually handicapped infants are referred to the Children's Department of Moorfields Eye Hospital each year. More than $80 \%$ have an obvious cause for their severely subnormal vision on ophthalmological or general physical examination (for example, cataracts, glaucoma, or albinism). In the remainder, examination of the media and fundi does not reveal the diagnosis, although some will go on to develop the characteristic retinal changes of Leber's amaurosis. Others will have cortical blindness. The remaining members of this category have been variously diagnosed. Doyne ${ }^{1}$ first drew attention to a small group of infants in whom the development of sight was only delayed and to the fact that a diagnosis of optic atrophy or of macular changes was mistakenly applied to members of this group in many instances. Electrodiagnostic techniques have enabled the distinction to be made at an early age between children with Leber's amaurosis, who will become permanently blind and whose condition is genetically determined, and other children with no apparent ocular abnormality to account for their poor visual response. ${ }^{17}$ The electroretinogram is extinguished or notably attenuated in Leber's amaurosis but is normal in the remaining members of his category. In cortical blindness the visually evoked response is absent. In 1980 Mellor and Fielder, ${ }^{10}$ in their series of four children with delayed visual maturation, reported normal electroretinograms but initially absent visually evoked responses. Serial electrodiagnostic tests on these children showed subsequent development of visually evoked responses with normal latencies but with abnormal wave forms. These eventually evolved into normal visually evoked responses when the children had well established visual responses. The authors regard these findings as evidence that the condition results from delayed dendritic and synaptic formation in the visual cortex rather than from delayed myelination of the optic nerve or delayed maturation of photoreceptors.

Confirmation of this view has recently come from Hoyt $e t a l,{ }^{12}$ who also found normal electroretinograms and initially abnormal visually evoked responses in their series of 8 children with delayed visual maturation. Though the latency of the first wave of the visually evoked potential was prolonged in some of their infants, the delay was not sufficiently long to imply that retarded myelination is a major factor. Most of their young patients had delayed motor development at the time of diagnosis, and one had nystagmus. The authors concur with Mellor and Fielder ${ }^{10}$ and Hoyt et al. ${ }^{12}$ Subsequently neither electrodiagnosis nor examination of the ocular fundi under general anaesthesia was deemed to be routinely necessary. Our experience with four children confirmed an impression that it was possible to distinguish between delayed visual maturation and the most probable alternative diagnosis of Leber's amaurosis on clinical grounds alone. The pupillary reaction to light in Leber's amaurosis is greatly impaired or absent from the outset of defective vision. Although three of our children showed nystagmus initially, the amplitude was small, and none resembled the gross pendular nystagmus characteristic of Leber's amaurosis. We consider normality of the pupillary responses and absence of roving eye movements to be strong pointers to a diagnosis of delayed visual maturation. We believe that the development of visual responses between 16 and 24 weeks of age, corrected for prematurity if necessary, in children with normal pupillary responses to light and no apparent structural defect of the eyes, justified our postponing an electroretinogram and examination under anaesthesia until persistent failure to see after this period should warrant such a step. Adopting this policy, we diagnosed no case of Leber's amaurosis as delayed visual maturation during the period of this study. The diagnosis of delayed visual maturation was considered in one child who presented at 12 weeks with apparently normal fundi but with sluggish pupillary reactions to light. When seen one month later she had developed roving eye movements. An electroretinogram was then performed and was normal, but a visually evoked response was abnormal and subsequent computed tomography showed septo-optic dysplasia.

Several authors have suggested that babies with delayed visual maturation are otherwise normal. ${ }^{8} 1011$ Follow up studies of our 16 patients do not bear this out. Although the visual prognosis for these infants who are 'slow to see' is excellent, a number of them develop neurological abnormalities. 


\section{References}

${ }^{1}$ Doyne PG. Amaurosis in infants. Practitioner 1930;125:174-8.

2 Doggart JH. Infantile fundus lesions in relation to mental capacity. Br Med J 1957;ii:933-5.

${ }^{3}$ Knox DL. Examination of the cortically blind infant. Am J Ophthalmol 1964;58:617-21.

${ }^{4}$ Nawratzki I, Landau L, Auerbach E. Belated visual maturation in a mentally retarded child. Journal of Pediatric Ophthalmology 1969;6:39-41.

5 Gordon N. Visual agnosia in childhood VI. Dev Med Child Neurol 1968;10:377-9.

${ }^{6}$ Illingworth RS. Dissociation as a guide to developmental assessment. Arch Dis Child 1958;33:118-22.

${ }^{7}$ Law F. The problem of the visually defective infant. Trans Ophthalmol Soc UK 1960;80:3-12.

8 Dudgeon J. Electrodiagnostic tests in visual assessment in children. Dispensing Optician 1977;29:222-9.

9 Illingworth RS. Delayed visual maturation. Arch Dis Child $1961 ; 36: 407-9$.

10 Mellor DH, Fielder AR. Dissociated visual development: electrodiagnostic studies in infants who are "slow to see". Dev Med Child Neurol 1980;22:327-55.
${ }^{11}$ Harel S, Holtzman M, Feinsod M. Delayed visual maturation. Arch Dis Child 1983;58:298-9.

12 Hoyt CS, Jastrzebski G, Marg E. Delayed visual maturation in infancy. Br J Ophthalmol 1983;67:127-30.

13 Vehrs S, Baum D. A test of visual responses in the newborn. Dev Med Child Neurol 1970;12:772-4.

14 Wolff PH, Ferber R. The development of behaviour in human infants, premature and newborn. Annu Rev Neurosci 1979;2:291-307.

15 Dubowitz L. A study of visual function in the premature baby. Child Care Health Dev 1979;5:399-404.

16 Wybar K. Recent advances in paediatric ophthalmology. $\mathrm{Br} \mathrm{J}$ Ophthalmol 1974;58:483-6.

17 Harden A, Pampiglione G. Neurophysiological approach to disorders of vision. Lancet 1970;i:805-8.

Correspondence to Dr R B Jones, Moorfields Eye Hospital, City Road, London EC1V 2PD.

Received 9 November 1983 